\title{
Participation and non-participation in FEMA's Community Rating System (CRS) program: Insights from CRS coordinators and floodplain managers
} Abdul-Akeem Sadiq ${ }^{\mathrm{a}}$, Jenna Tyler ${ }^{\mathrm{a}, ",}$, Douglas Noonan ${ }^{\mathrm{b}}$

${ }^{a}$ University of Central Florida, 528 W Livingston Street, United States

${ }^{\mathrm{b}}$ Indiana University-Purdue University Indianapolis, United States

ABSTRACT Given that floods cause the greatest economic impact and affect more communities annually than any other natural hazard, there is a compelling need to better understand how communities can enhance their resilience to future flood disasters. One mechanism for enhancing communities' resilience to future flood disasters is through participation in the Federal Emergency Management Agency's (FEMA) Community Rating System (CRS). The CRS is a federal voluntary program that incentivizes communities in the United States to implement floodplain management activities that exceed those required under the National Flood Insurance Program (NFIP). In ex-change for engaging in additional floodplain management activities, policyholders residing in CRS-participating communities receive discounts in their flood insurance premiums. To better understand the factors driving CRS participation, this study uses propensity score matching to match 100 randomly selected CRS participating communities with 100 non-CRS participating communities. Data gathered from CRS coordinators and floodplain managers indicate several factors are responsible for why communities participate, continue to participate, or do not participate the CRS. The main reason for participating in the CRS and continuing to participate is the reduction in flood insurance premiums, while the main reason for not joining the CRS is lack of resources (staff, funding, and time).

\section{Keywords:}

Community Rating System (CRS)

Community flood risk management

Flooding

Floodplain manager

CRS coordinator

\section{Introduction}

Flooding remains the most destructive natural hazard both in the United States and around the globe [1]. According to the National Weather Service (NWS), 116 individuals were killed, on average, as a result of flooding between 2008 and 2017 [2]. Studies also show that over the past 30 years, floods have caused over $\$ 7$ billion in damages per year [2]. Recent disasters provide contextual evidence of the impact floods can have on local communities. The 2016 Louisiana floods, for example, dropped over 30 inches of rainfall in some communities and led to over $\$ 8$ billion in damage [3]. Furthermore, Hurricane Harvey devastated much of southeastern Texas in August 2017 as it dropped over 60 inches of rainfall over an eight-day period [4].

Since floods cause the greatest economic impact and affect more communities annually than any other natural hazard [1,5], there is a compelling need to better understand how communities can enhance their resilience to future flood disasters [6]. One mechanism for enhancing communities' resilience to future flood disasters is through participation in the Federal Emergency Management Agency's (FEMA)
Community Rating System (CRS) program. The CRS is a federal voluntary program created in 1990 to incentivize communities in the United States to implement floodplain management activities that exceed those required under the National Flood Insurance Program (NFIP). In exchange for adopting additional flood mitigation measures, policyholders residing in CRS-participating communities receive discounts in their flood insurance premiums.

Despite a growing body of research indicating CRS participating communities experience fewer flood losses [7-13], only about five percent of communities that participate in the NFIP also participate in the CRS [14]. This low participation has prompted scholars to examine the predictors of CRS participation, primarily by gathering data on the observable factors that are readily available through secondary sources like the United States Census Bureau (e.g., data on population density and median housing income). Scholars have yet to gather data on the unobservable predictors of CRS participation. By unobservable predictors, we do not mean factors that cannot be measured or identified [15]. Rather, we mean the factors that determine whether or not a community participates in the CRS but cannot be easily measured due to

\footnotetext{
* Corresponding author.

E-mail addresses: abdul-akeem.sadiq@ucf.edu (A.-A. Sadiq), jentyler@knights.ucf.edu (J. Tyler), noonand@iupui.edu (D. Noonan).
}

This is the author's manuscript of the article published in final edited form as: 
a lack of primary data (e.g., data on the specific reasons why communities decide to participate or not participate in the CRS). The purpose of this study is, thus, to fill this void in research and answer the following research questions: (1) What unobservable factors motivate communities to begin participating in the CRS? (2) What unobservable factors motivate communities to continue participating in the CRS? (3) What unobservable factors motivate communities to not participate in the CRS? To answer these questions, we use propensity score matching (PSM) to match 100 randomly selected CRS participating communities with 100 non-CRS participating communities. Then, we conduct phone interviews with CRS coordinators in CRS participating communities and floodplain managers in non-CRS participating communities.

This study contributes to the community flood risk management literature in general and the CRS scholarship in particular by providing insights on the unobservable predictors of CRS participation through semi-structured interviews that gathered both quantitative and qualitative data. This approach is novel and much needed as the vast majority of CRS participation studies employ quantitative methods and rely on secondary data sources (see Refs. [9,16-21]). Obtaining the unique perspectives of CRS coordinators and floodplain managers will advance our understanding of the unobservable drivers of CRS participation and will offer important insights regarding the decision-making process surrounding community flood risk management. Furthermore, the identification of such unobservable drivers will help policymakers design appropriate tools to encourage communities to participate in the CRS and other federal voluntary programs.

\section{Literature review}

\subsection{Background on CRS program}

The CRS is a federal voluntary program designed to incentivize communities to implement floodplain management activities that go beyond those required under the NFIP. However, unlike the NFIP, FEMA established the CRS program to be actuarially sound, meaning the discounts provided in flood insurance rates were intended to reduce the number of flood insurance claims [22]. The goals of the CRS include, "reducing flood damage to insurable property, strengthening and supporting the insurance aspects of the NFIP, and encouraging a comprehensive approach to floodplain management" [14]; p. 1). When communities engage in floodplain management activities that reflect these three goals, local residents receive reductions in their flood insurance premiums based on their CRS class and whether or not they are located in a Special Flood Hazard Area (SFHA). An SFHA refers to a place where there is at least a one percent chance of flooding in any given year.

Communities are organized into 10 classes. A class 10 community represents communities that do not participate in the CRS or have not accumulated at least 500 credit points; these communities do not receive any reductions in flood insurance premiums. A class 1 community represents communities that have obtained the maximum amount of credit points; these communities receive a $45 \%$ reduction in flood insurance premiums. Intermediate classes receive discounts in flood insurance in increments of $5 \%$ (so long as the community is located in a SFHA) (see Table 1).

CRS classes and associated discounts in flood insurance premiums are determined based on the amount of credit points communities have accumulated. Communities accumulate credit points by implementing any of the CRS's 19 creditable activities [14]. FEMA organizes CRS activities into four categories: public information, mapping and regulations, flood damage reduction, and warning and response (see Table 2). Activities included under public information category (300 series) aim to inform individuals about flood hazards and ways to reduce flood losses such as through the purchasing of flood insurance. Mapping and regulation activities (400 series) seek to protect new development and natural floodplain functions, preserve open space, enforce higher
Table 1

CRS classes, credit points, and premium discounts based on location in or outside an SFHA.

\begin{tabular}{llll}
\hline \multirow{2}{*}{ CRS Class } & Credit Points & \multicolumn{2}{l}{ Premium Reduction } \\
\cline { 3 - 4 } & & In SFHA (\%) & Outside SFHA (\%) \\
\hline 1 & $4500+$ & 45 & 10 \\
2 & $4000-4999$ & 40 & 10 \\
3 & $3500-3999$ & 35 & 10 \\
4 & $3000-3499$ & 30 & 10 \\
5 & $2500-2999$ & 25 & 10 \\
6 & $2000-2499$ & 20 & 10 \\
7 & $1500-1999$ & 15 & 5 \\
8 & $1000-1499$ & 10 & 5 \\
9 & $500-999$ & 5 & 5 \\
10 & $0-499$ & 0 & 0 \\
\hline
\end{tabular}

Source: FEMA [14].

Table 2

Credit points awarded for CRS activities.

\begin{tabular}{|c|c|c|}
\hline Activity & $\begin{array}{l}\text { Maximum Possible } \\
\text { Points }\end{array}$ & $\begin{array}{l}\text { Percent of Communities } \\
\text { Credited }\end{array}$ \\
\hline \multicolumn{3}{|c|}{300 Public Information Activities } \\
\hline 310 Elevation Certificates & 116 & 96 \\
\hline $\begin{array}{l}320 \text { Map Information } \\
\text { Service }\end{array}$ & 90 & 85 \\
\hline 330 Outreach Projects & 350 & 93 \\
\hline 340 Hazard Disclosure & 80 & 84 \\
\hline $\begin{array}{l}350 \text { Flood Protection } \\
\text { Information }\end{array}$ & 125 & 87 \\
\hline $\begin{array}{l}360 \text { Flood Protection } \\
\text { Assistance }\end{array}$ & 110 & 41 \\
\hline $\begin{array}{l}370 \text { Flood Insurance } \\
\text { Promotion }\end{array}$ & 110 & 4 \\
\hline \multicolumn{3}{|c|}{400 Mapping and Regulations } \\
\hline 410 Floodplain Mapping & 802 & 55 \\
\hline $\begin{array}{l}420 \text { Open Space } \\
\text { Preservation }\end{array}$ & 2020 & 89 \\
\hline $\begin{array}{l}430 \text { Higher Regulatory } \\
\text { Standards }\end{array}$ & 2042 & 100 \\
\hline $\begin{array}{l}440 \text { Flood Data } \\
\text { Maintenance }\end{array}$ & 222 & 95 \\
\hline $\begin{array}{l}450 \text { Stormwater } \\
\text { Management }\end{array}$ & 755 & 87 \\
\hline \multicolumn{3}{|c|}{500 Flood Damage Reduction Activities } \\
\hline $\begin{array}{l}510 \text { Floodplain Mgmt. } \\
\text { Planning }\end{array}$ & 622 & 64 \\
\hline $\begin{array}{l}520 \text { Acquisition and } \\
\text { Relocation }\end{array}$ & 2250 & 28 \\
\hline 530 Flood Protection & 1600 & 13 \\
\hline $\begin{array}{l}540 \text { Drainage System } \\
\text { Maintenance }\end{array}$ & 570 & 43 \\
\hline 600 Warning and Response & & \\
\hline $\begin{array}{l}610 \text { Flood Warning and } \\
\text { Response }\end{array}$ & 395 & 20 \\
\hline 620 Levees & 235 & 0.5 \\
\hline 630 Dams & 160 & 35 \\
\hline
\end{tabular}

Source: FEMA [14].

regulatory standards, manage stormwater, and develop Flood Insurance Rate Maps (FIRMs). Activities included under flood damage reduction (500 series) include developing a comprehensive floodplain management plan, maintaining drainage systems, and relocating or retrofitting flood-prone structures. Finally, warning and response (600 series) activities consist of measures that protect life and property during a flood event such as developing programs to warn community members about flood events and maintaining levees and dams.

Despite the benefits of reduced flood insurance premiums and lower flood risks, as of 2017, only five percent of communities that participate in the NFIP also participate in the CRS [14]. Furthermore, of the nearly 1500 participating CRS communities, only one community has a class 1 rating, and only six communities have a class 2 rating [23]. Most CRS 
participating communities fall in the class range of 5 through 9 [23]. Given such low participation, there is a need to better understand the unobservable factors driving and inhibiting CRS participation [21]. Before reviewing the extant literature on the factors influencing CRS participation, we look at the emergence and participation in voluntary programs more broadly, and in particular, voluntary environmental programs.

\subsection{Voluntary programs}

Over the past few decades, there has been a growing interest in using voluntary programs as a policy tool to help address the ineffectiveness and costliness of command-and-control approaches [24]. Indeed, top-down, command-and-control regulatory approaches have been criticized for their rigidity and costliness [25-27]. Consider, for example, the Clean Air Act. Designed to control air pollution, this Act increased organizations' operating costs, which in turn, reduced their productivity and profits [27]. According to Lyons and Maxwell [26]; voluntary programs have become more popular as they can help reduce compliance and transaction costs. Moreover, Potoski and Prakash [27] as well as Arimura, Hibiki, and Katayama [25] advocate using voluntary programs as a supplement due to the high compliance costs associated with traditional command-and-control approaches. Finally, Berke [28] suggests using voluntary programs in conjunction with traditional regulatory approaches to incentivize local governments to engage in additional natural hazard risk-management activities. Despite the inherent benefits of voluntary programs, namely increased compliance rates, many federal voluntary programs are finding it hard to increase their compliance and/or participation rates.

Myriad studies have explored why private organizations participate in voluntary environmental programs (VEPs), with the intent to determine how best to increase participation rates (e.g., Ref. [29-32].

Khanna [33] argues that participation in VEPs hinges on the costs and benefits. That is, private organizations tend to participate in VEPs only when the benefits are greater than the costs associated with participating. Other studies on VEPs have shown that market-based incentives also influence private organizations' decision to participate in VEPs $[34,35]$. The United States Environmental Protection Agency's (EPA) WasteWise program is a good example. This program aimed to reduce municipal solid wastes and provides both financial (e.g., reduced waste disposal costs) and non-financial (e.g., recognition awards) incentives to participants [36]. In summary, extant research shows that organizations tend to estimate their benefit-cost ratios, and that a community will participate voluntary programs only when the benefits outweigh the costs [33]

\subsection{Research on the CRS program}

The number of studies on the CRS has significantly increased over the past decade [21]. This prompted Sadiq and colleagues [21] to conduct the first systematic review of academic research on the CRS. Their study not only provides important information regarding the current state of knowledge on the CRS, but it also identifies research gaps and offers practical recommendations and policy recommendations to emergency and floodplain managers and policymakers, respectively [37]. This systematic review showed that scholars have examined various aspects of the CRS program, including whether the program is effective at reducing flood losses $[7,9-13,16,38-41])$, the value and effectiveness of specific CRS activities [9,10,13,41-46], and the predictors of CRS scores, ratings, and points [20,43,46-50]. Scholars have also examined the relationship between the CRS and disaster recovery [51,52], poverty and income inequality [53], as well as migration and development [54].

Identifying the determinants of CRS participation - the focus of the present study - has also received some attention (see Ref. [12,16,17,20, $46,49]$. The results from the reviewed studies showed that communities participating in the CRS have greater flood risks and higher population sizes [16,20], educational attainment levels [9,17], incomes [18,19], tax revenues [17], proportion of senior citizens [17] as well as lower crime and unemployment rates [17]. Other scholars (e.g., Ref. [20] found that communities with higher local capacity, measured as community payroll, are more likely to participate in the CRS. In summary, flood risks, political economy, local capacity, and socio-economic factors have been shown to be significant predictors of CRS participation. Furthermore, all of the studies examining the predictors of CRS participation used quantitative methodologies and secondary data [37].

The present study contributes to this growing body of research by interviewing the individuals responsible for flood management decisionmaking at the community level-CRS coordinators and floodplain managers - to identify the unobservable predictors of CRS participation. To our knowledge, this is the first national-level study to investigate the unobservable predictors of initial, continued, and non-CRS participation.

\subsection{The role of CRS coordinators and floodplain managers}

In the United States, floodplain management ordinances and administrative requirements vary widely due to differences in state law and statutory authority [55].). However, despite such variations, states generally grant local communities the power and authority to adopt, administer, and enforce floodplain management regulations [55]. Elected officials usually identify a subordinate to delegate power and authority to serve as the community's floodplain manager. Depending on the structure and size of a community, the floodplain manager might also serve as the community development director, zoning officer, building code official, engineer, or planner. The primary responsibilities of the floodplain manager include "enforcing the community's flood damage prevention ordinance, updating flood maps, plans, and policies of the community, and any of the activities related to the administration of the NFIP" [56]; p. 1) such as understanding regulations, correcting violations, processing permit applications, ensuring projects are built according to approved permits, and taking action to resolve noncompliant activities [55].

In communities that participate in the CRS, the floodplain manager usually serves as the CRS coordinator. CRS coordinators maintain the same responsibilities as the floodplain manager, but also oversee all aspects of participation in the CRS, including but not limited to, the identification and implementation of creditable activities, the maintenance of relevant documentation, and the coordination of verification and recertification activities [23].). It is important to note that the CRS coordinator does not and is not always a community employee; communities, for example, can choose to contract CRS responsibilities out to a private agency or firm [23].

\section{Data and methods}

\subsection{Matching procedure}

A random sample of 100 CRS communities was selected from the sample of 21,804 communities for which we had CRS participation data and other covariates. To be eligible to be drawn into the sample, the communities must have been in the list of CRS communities as of 2013 (CRS13 = 1) and have a propensity score (i.e., have observed values of all covariates). This included 1169 communities out of the 1172 communities in the CRS. The covariates used in this study consist of socioeconomic and flood-risk-related variables found to be significant predictors of CRS participation by previous studies (e.g., Ref. [9,17-20, 57]). The socioeconomic variables include population density, share of the population that is white, share of the population aged 18 and older, share of the population under age 5 , share of the population with at least a college degree, share of the households that lived in same county 5 years prior, share of the population below the poverty level, log of the median family income, log of the median housing value (mean of the 
tract-level medians), log of the aggregate housing value, and share of the housing units that are rented. Data on these socioeconomic variables were derived from the 2010 Census. The flood-related variables include the county-level flood event damage from the Spatial Hazard Events and Loss Database for the United States (SHELDUS) for 2007-2012, the flood damage in 2012, a dummy variable for whether the community had a digital Flood Insurance Rate Map available in 2013, the average flood risk for the county, and the population-weighted flood risk for the county.

For the full sample of 21,804 communities, we conducted a propensity score matching exercise in Stata to generate propensity scores for all the observations. The propensity score matching procedure involves identifying the four nearest neighbors for each of the 100 randomly selected observations, where the treatment variable is CRS13 and the covariates are the socioeconomic and flood-risk-related variables listed above. Propensity scores are based on a logit to estimate, and a common support constraint is imposed to ensure all treatment observations' propensity scores are not higher than the maximum or lower than the minimum propensity scores of the untreated observations. Only two observations lacked support.

We then use the propensity scores to identify (untreated) matches for the randomly selected 100 (treated) observations. Rather than compare some outcome variable for the treated observations with the outcome variable for their nearest neighbors, we use the propensity scoring just to identify the matches. Matches can be city-to-city, county-to-county, cityto-county or county-to-city. PSM is used to condition the comparisons between treated and untreated observations such that the pair of observations are nearly identical in terms of their likelihood of participating in the CRS. In short, PSM uses observable factors that predict participation in the CRS to control for differences between the treated and untreated observations. This ensures that the selection into treatment is essentially random or at least unrelated to the outcomes. This approach allows us to then use interview questions to investigate how each of the 100 matched pairs differs on unobservables factors.

\subsection{Questionnaire}

We designed two interview scripts in August 2018-one for CRS communities and the other for non-CRS communities, with many overlapping questions. Questions on both interview scripts include, but are not limited to, demographic characteristics such as age and educational level; job-related questions like position, role, and tenure; organizational characteristics such as the number of full-time employees; community's capacities and constraints regarding flood mitigation, preparedness, response, and management; how community flood risk management decisions are made. For the non-CRS script, we include some background information about the CRS. The interview scripts diverge when questions about the CRS are asked. For example, communities that participate in the CRS program were asked "To the best of your knowledge, what are the reasons why your community initially decided to participate in the CRS? and "To the best of your knowledge what are the reasons why your community continues to participate in the CRS?" Non-CRS Participating communities were asked, "What are the reasons, if you know of any, that your community has not participated in the CRS?" The interviews contained both open- and closedended questions as well as quantitative and qualitative components.

In September 2018, we pretested the CRS interview script and the non-CRS interview script with three CRS coordinators and one floodplain manager, respectively. No major changes to the two interview scripts were made. The interview scripts were then given to a research institute in a university located in the United States. The interview process began in October 2018. To reduce interviewer bias, all research staff that participated in data collection went through a training session on proper policies and procedures of conducting ethical research. This study was approved by the Institutional Review Board of the university where the study was conducted.

\subsection{The interview process}

After randomly selecting $100 \mathrm{CRS}$ communities (treatment/CRS group) and their four non-CRS (untreated/non-CRS group) respective matched pairs, a series of phone interviews were conducted by the research institute. Two sets of interviews were conducted. The first set is for the CRS coordinators for the 100 randomly selected treatment/CRS group. The second set of interviews is for the CRS group's respective 100 matches (treatment/non-CRS group). For this latter group, interviews were conducted with the floodplain manager.

To identify the CRS coordinators and floodplain managers, we utilized the lists provided by state mitigation officers and official community websites. The research team obtained the names, phone numbers, and e-mails of the CRS coordinators and floodplain managers from these two sources and gave the information to the research institute. The interviewers from the research institute contacted the CRS coordinators first via email or phone in groups of 25 to ensure all communication remained organized. After completing 50 CRS interviews, the corresponding non-CRS matches were contacted as well.

To get in contact with the appropriate person to conduct the interview with, individual emails were sent to all the email addresses provided. After one week of receiving no response to the initial email, the research institute interviewers began calling the phone numbers associated with the emails. Each number was called no more than one time per day and no more than three times per week to get an interview either completed or scheduled for completion later. After one month of receiving no response from certain communities, a follow-up email was sent to them requesting their participation in the interview. The research institute interviewers continued to call these communities daily for several weeks after the follow up email. For communities that still proved difficult to reach, a different way to contact them was established. Specifically, individuals were identified by searching through their official community websites to see if there was a specific department that deals with floodplain management. If no such department existed, a search was performed on the website for other related departments where the CRS coordinator or floodplain manager may be located such as the Engineering Department, Building Department, Planning Department, Community Development Department, and Public Works Department.

In contacting officials from these departments, it was the goal that if they were not the appropriate person we needed to speak with, they would at least be able to put us in contact with or provide us contact information for the appropriate individuals. If an email address was provided on the community's website, the same procedures were followed, allowing them time to respond to the email before calling their office. If an email address was not provided, but a phone number was, the research institute interviewers called the office numbers and either completed the interview or scheduled the interview for another time. To make sure the right individuals were those interviewed, all participants confirmed with the research institute interviewers at the beginning of the interview that they served as either the CRS coordinator or the floodplain manager before proceeding further with the interview. The average length of the phone interviews for the treatment/CRS group and the untreated/non-CRS group were about 25 and $15 \mathrm{~min}$, respectively. All 200 interviews were completed in August 2019.

\subsection{Coding procedure}

We employed a mixture of deductive and inductive coding techniques to analyze the interview responses. Deductive coding refers to identifying codes in accordance to theory or prior research [58]. Based on theory and the extant CRS participation literature, we identified a series of open codes. Open coding entails reviewing, identifying, and organizing texts into broad categories [58]. We identified the following open codes as reasons why communities decide to begin participating in the CRS: prior flood experience, copycatting, and benefits. The only 
open code we identified for continued participation is benefits. We identified additional open codes for why communities begin and continue to participate in the CRS like high flood risk and community composition. However, we did not include these because they did not contain enough responses. Finally, the open codes we identified as reasons why communities decide not to participate in the CRS include: lack of resources, lack of benefits, and costs.

For the codes that did not align with any of the previous open codes, we used inductive coding. Inductive coding refers to identifying themes solely based on the data itself [58]. We identified the following inductive open codes for initial participation: education, outreach, and/or awareness; and other. The inductive open codes for continued participation include: education, outreach, and/or awareness; political reasons; past participation; already doing the activities; flood management program maintenance, evaluation, and improvement; improve rating; and other. Finally, the inductive open codes we identified for communities that do not participate in the CRS include: administrative burden; political reasons; and other. See Table 3 for a description of each open code used through the deductive and inductive coding process (deductive open codes are shaded gray).

After identifying all the open codes, we reviewed the interview responses again to develop sub-codes. These sub-codes illustrate different concepts represented by an open code. For example, "reduced flood insurance premiums" represents a sub-code under the open-code category "benefits." To better ensure inter-coder reliability through the coding process, two of the authors individually coded each interview response. These two individuals then met to discuss any discrepancies. All discrepancies were resolved through consensus.

\section{Results}

In this section, we first present the results of the descriptive statistics of those interviewed and then the results of the coding analyses. According to Table 4, which presents the descriptive statistics, the positions of CRS coordinator and floodplain manager are dominated by men. Specifically, $68 \%$ of CRS coordinators and $77 \%$ of floodplain managers are men. Also, $43 \%$ of CRS coordinators and floodplain managers are between the ages of 45 and 59 years. In addition, almost half of the CRS coordinators and floodplain managers interviewed have a Bachelor's degree. Finally, $45 \%$ of CRS coordinators have been at their jobs for 3-8 years, while $31 \%$ of floodplain managers have been at their job for the same duration.

We organize the coding analyses results into three sections-reasons for initial CRS participation, reasons for continued CRS participation, and reasons for not participating in the CRS. The total number of codes for each category exceeds the total number of respondents because some respondents listed multiple reasons for why their community does, continues to, or does not participate in the CRS. It is important to note that the phone interviews were not audio recorded. Instead, the research institute interviewers typed respondents' answers as they were conducting the interview; therefore, we do not provide any direct quotes from respondents. See Table 5 below for a summary of the open and sub codes.

\subsection{Reasons for initial CRS participation}

We identified five open codes for why communities initially decide to participate in the CRS. These include: prior flood experience $(N=3)$, copycatting $(N=4)$, education, awareness, and/or outreach $(N=5)$, benefits $(N=75)$, and other $(N=14)$. Benefits was the only open code where we were able to identify additional sub-codes, which include: general benefits $(N=7)$, reduced flood insurance premiums $(N=36)$, address flood risks and reduce flood losses $(N=6)$, flood mitigation, protection, and response $(N=4)$, improve land use, strengthen local ordinances, and preserve natural areas $(N=7)$, community and/or homeowner $(N=8)$, and cost savings $(N=7)$. The code 'other' included any response that did not correspond with any of the previously identified open codes and that did not have at least three respondents citing that specific reason. For example, two respondents mentioned maintaining compliance as a reason for initial CRS participation. These two responses stayed under the 'other' code because they did not have the three responses needed to become their own code.

\subsubsection{Prior flood experience}

Three respondents reported prior flood experience influenced their community's decision to participate in the CRS. One respondent specifically mentioned their community began participating in the CRS soon after a major hurricane impacted their community. Another respondent reported they began participating because they do not want to see their community flooded again. The final respondent mentioned they began participating in response to serious flooding and property damage.

\subsubsection{Copycatting}

Four respondents stated they began participating in the CRS because they were influenced by other communities' participation. Three respondents specifically mentioned their communities began participating because the other communities around them were participating. One respondent also noted that surrounding communities began participating so their community started participating to remain in good status as a community.

\subsubsection{Education, outreach, and/or awareness}

Five respondents reported they began to participate in the CRS for the education, outreach, and/or awareness opportunities. For example, one respondent noted that the outreach efforts by personnel with FEMA and the NFIP influenced their community's decision to participate. Two other respondents revealed the educational component associated with the CRS motivated their community to participate.

\subsubsection{Benefits}

Benefits represented the largest open code category, containing a total of 75 responses that generated seven sub-codes (in italics). Seven respondents reported that the general benefits associated with the program prompted their community's initial participation in the CRS. Other respondents identified more specific reasons. The most popular reason was the reduced flood insurance premiums for flood insurance policyholders within their community. Specifically, 36 respondents reported this as a reason contributing to their decision to participate in the CRS. In addition, six respondents reported they began participating in the CRS as a means to address flood risks and reduce future flood losses. Of these five respondents, three mentioned they began participating to reduce flood losses. Another two reported they participate because a portion of their community resides in a floodplain. Flood mitigation, protection, and response represents an additional benefit reported by four respondents. These respondents specifically mentioned they began participating in the CRS to be prepared, increase their level of protection, and improve their ability to mitigate flood hazards. Seven respondents cited the possibility to improve land use, strengthen local ordinances, and preserve natural areas motivated their community to participate in the CRS. Two of these respondents specifically reported they began participating in the CRS to help prevent development in flood prone areas. Another reported they wanted to make sure the community was built safely. Eight respondents mentioned they began participating in the CRS to benefit the community and/or homeowner. Finally, seven respondents stated their community initially began participating in the CRS to experience cost savings. One of these respondents further noted they initially began participating because it was free to do so.

\subsubsection{Other}

Fourteen responses were included under the code titled, 'other.' Two respondents mentioned their community began participating in the CRS 
Table 3

Open codes developed through deductive and inductive coding process.

\begin{tabular}{|c|c|c|}
\hline \multirow{6}{*}{$\begin{array}{l}\text { Why communities } \\
\text { initially participate in } \\
\text { the CRS }\end{array}$} & Open Code & $\begin{array}{l}\text { Description } \\
\end{array}$ \\
\hline & Prior Flood Experience & $\begin{array}{l}\text { Responses reference that their community has } \\
\text { experienced prior flood disaster(s) }\end{array}$ \\
\hline & Copycatting & $\begin{array}{l}\text { Responses reference participating because a } \\
\text { neighboring community participates in the } \\
\text { CRS }\end{array}$ \\
\hline & Benefits & $\begin{array}{l}\text { Responses reference a benefit of participating } \\
\text { in the CRS }\end{array}$ \\
\hline & $\begin{array}{l}\text { Education, Outreach, and/or } \\
\text { Awareness }\end{array}$ & $\begin{array}{l}\text { Responses reference education, outreach, } \\
\text { and/or awareness opportunities }\end{array}$ \\
\hline & Other & $\begin{array}{l}\text { Responses do not correspond with any of the } \\
\text { previously identified codes }\end{array}$ \\
\hline \multirow{8}{*}{$\begin{array}{l}\text { Why communities } \\
\text { continue to participate } \\
\text { in the CRS }\end{array}$} & Benefits & $\begin{array}{l}\text { Responses reference a benefit of participating } \\
\text { in the CRS }\end{array}$ \\
\hline & $\begin{array}{l}\text { Education, Outreach, and/or } \\
\text { Awareness }\end{array}$ & $\begin{array}{l}\text { Responses reference education, outreach, } \\
\text { and/or awareness opportunities }\end{array}$ \\
\hline & Political Reasons & $\begin{array}{l}\text { Responses reference local politics or elected } \\
\text { officials }\end{array}$ \\
\hline & Past Participation & $\begin{array}{l}\text { Responses reference they have always } \\
\text { participated in the CRS }\end{array}$ \\
\hline & $\begin{array}{l}\text { Already Doing the } \\
\text { Activities }\end{array}$ & $\begin{array}{l}\text { Responses reference that the community is } \\
\text { already doing activities associated with the } \\
\text { CRS }\end{array}$ \\
\hline & $\begin{array}{l}\text { Flood Management Program } \\
\text { Maintenance, Evaluation, } \\
\text { and Improvement }\end{array}$ & $\begin{array}{l}\text { Responses reference they continue to } \\
\text { participate for flood management program } \\
\text { maintenance, evaluation, or improvement } \\
\text { purposes }\end{array}$ \\
\hline & Improve Rating & $\begin{array}{l}\text { Responses reference a desire to improve their } \\
\text { CRS rating }\end{array}$ \\
\hline & Other & $\begin{array}{l}\text { Responses do not correspond with any of the } \\
\text { previously identified codes }\end{array}$ \\
\hline \multirow{6}{*}{$\begin{array}{l}\text { Why communities do } \\
\text { not participate in the } \\
\text { CRS }\end{array}$} & Lack of Resources & $\begin{array}{l}\text { Responses reference that they lack resources } \\
\text { to participate in the CRS }\end{array}$ \\
\hline & Lack of Benefits & $\begin{array}{l}\text { Responses reference that participation in the } \\
\text { CRS does or would not yield benefits }\end{array}$ \\
\hline & Costs & $\begin{array}{l}\text { Responses reference that participation in the } \\
\text { CRS is costly }\end{array}$ \\
\hline & Administrative Burden & $\begin{array}{l}\text { Responses reference that participation } \\
\text { requires too much paperwork }\end{array}$ \\
\hline & Political Reasons & $\begin{array}{l}\text { Responses reference local politics or elected } \\
\text { officials }\end{array}$ \\
\hline & Other & $\begin{array}{l}\text { Responses do not correspond with any of the } \\
\text { previously identified codes }\end{array}$ \\
\hline
\end{tabular}


Table 4

Descriptive statistics of CRS coordinators and floodplain managers.

\begin{tabular}{lll}
\hline Variable & $\begin{array}{l}\text { CRS } \\
\text { Coordinators } \\
\%\end{array}$ & $\begin{array}{l}\text { Floodplain } \\
\text { Managers } \\
\%\end{array}$ \\
\hline Gender & & \\
Male & 68 & 77 \\
Female & 32 & 23 \\
Age & & \\
27-44 & 28 & 30 \\
45-59 & 43 & 43 \\
Over 60 & 23 & 24 \\
No Response & 6 & 3 \\
Education & & \\
High School Graduate & 2 & 4 \\
Some College or Technical School & 11 & 8 \\
AA/AS Degree (2 Year College Deg.) & 11 & 6 \\
Bachelor's Degree (College Graduate) & 47 & 45 \\
Postgraduate Degree (Master's, PhD., J. & 29 & 37 \\
$\quad$ D.) & & \\
Tenure & & 21 \\
Less Than 3 Years & 18 & 31 \\
3-8 Years & 45 & 23 \\
9-14 Years & 19 & 12 \\
15-20 Years & 6 & \\
Over 20 Years & 12 & \\
\hline
\end{tabular}

to ensure compliance. Another respondent stated there are many flood insurance policyholders within their community. In addition, one respondent indicated their community began participating in the program because it was new, and another stated their community wanted to take a more progressive approach. Other respondents noted the desire to improve their flood maintenance strategy, to receive better flood maps, and because their community was already doing the activities. A final respondent indicated the potential for increased property values

Table 5

Summary of open and sub codes for initial, continued, and Non-CRS participation.

\begin{tabular}{|c|c|c|c|}
\hline Code & Initial & Continued & $\begin{array}{l}\text { Non- } \\
\text { Participation }\end{array}$ \\
\hline Prior Flood Experience & 4 & - & - \\
\hline Copycatting & 3 & - & - \\
\hline Education, Outreach, and/or Awareness & 5 & 17 & - \\
\hline Benefits & 75 & 99 & - \\
\hline General & 7 & 5 & - \\
\hline Reduced Flood Insurance Premiums & 36 & 58 & - \\
\hline $\begin{array}{l}\text { Address Flood Risks and Reduce Flood } \\
\text { Losses }\end{array}$ & 6 & 5 & - \\
\hline $\begin{array}{l}\text { Flood Mitigation, Protection, and } \\
\text { Response }\end{array}$ & 4 & 8 & - \\
\hline $\begin{array}{l}\text { Improve Land Use, Strengthen Local } \\
\text { Ordinances, and Preserve Natural Areas }\end{array}$ & 7 & 9 & - \\
\hline Community and/or Homeowner & 8 & 8 & - \\
\hline Cost Savings & 7 & 6 & - \\
\hline Political Reasons & - & 4 & 3 \\
\hline Past Participation & - & 4 & - \\
\hline Already Doing the Activities & - & 3 & - \\
\hline $\begin{array}{l}\text { Flood Management Program } \\
\text { Maintenance, Evaluation, and } \\
\text { Improvement }\end{array}$ & & 7 & - \\
\hline Improve Rating & - & 3 & - \\
\hline Lack of Resources & - & - & 36 \\
\hline General & - & - & 7 \\
\hline Staff & - & - & 17 \\
\hline Funding & - & - & 4 \\
\hline Time & - & - & 8 \\
\hline Lack of Benefits & - & - & 4 \\
\hline Costs & - & - & 12 \\
\hline General & - & - & 3 \\
\hline Costs Outweigh Benefits & - & - & 9 \\
\hline Administrative Burden & - & - & 7 \\
\hline Other & 14 & 20 & 13 \\
\hline
\end{tabular}

prompted the community to begin participating in the CRS.

\subsection{Reasons for continued CRS participation}

We identified eight open codes for why communities continue to participate in the CRS. These include: education, outreach, and/or awareness $(N=17)$, benefits $(N=99)$, political reasons $(N=4)$, past participation $(N=4)$, already doing the activities $(N=3)$, flood management program maintenance, evaluation, and improvement $(N=7)$, improve rating $(N=3)$, and other $(N=20)$. Benefits, again, was the only open code where we were able to identify additional sub-codes (in italics), which include: general benefits $(N=5)$, reduced flood insurance premiums $(N=58)$, flood mitigation, protection, and response $(N=8)$, address flood risks and reduce flood losses $(N=5)$, improve land use, strengthen local ordinances, and preserve natural areas $(N=9)$, community and/or homeowner $(N=8)$, and cost savings $(N=6)$. Recall, the code 'other' included any responses that did not correspond with any of the previously identified open codes and that did not have at least three respondents reporting that specific reason.

\subsubsection{Education, outreach, and/or awareness}

Seventeen respondents reported they continue to participate in the CRS because of the education, outreach, and/or awareness opportunities. Seven of these respondents specifically noted they continue to participate in the CRS as a means to educate and keep the public aware of flood risks and community floodplain management. The other respondents discussed education, outreach, and/or awareness in more general terms.

\subsubsection{Benefits}

Benefits remained the largest open code category, containing a total of 99 responses and generating seven sub-codes (in italics). Five respondents reported they continue to participate in the CRS for the general benefits, and 58 respondents stated they continue to participate for the reduced flood insurance premiums. In addition, eight respondents mentioned they continue participating in the CRS to improve their flood mitigation, protection, and response. Three and four respondents reported they continue to participate to help mitigate flood damage and protect the community, respectively. One respondent mentioned the CRS helps their community ensure they are ready to react to disasters. Five respondents reported they continue participating in the CRS as a means to address flood risks and reduce future flood losses. Of these five respondents, three specifically mentioned they began participating to reduce flood losses and lower the risk to property owners. Another three reported they continue to participate because their community is prone to flooding. Improve land use, strengthen local ordinances, and preserve natural areas represents another reason for continued participation. Five of the nine respondents reported they continue to participate in the CRS to enforce their floodplain ordinance and to maintain higher regulatory standards. Another two mentioned they continue to participate to help ensure they are engaging in smarter development. Eight respondents mentioned they continue participating in the CRS to benefit the community and/or homeowner. Finally, six respondents stated the cost savings contribute to their community's decision to continue participating in the CRS.

\subsubsection{Political reasons}

Four respondents mentioned they continue to participate in the CRS because of various political reasons. For example, one respondent mentioned they continue to participate in the CRS because they have political support. Another stated the town council still wants the community to participate, and another reported they continue to participate because their community is a pro-environment community. Finally, one respondent stated that they thought it would be too big of a political scandal to stop participating in the CRS. 


\subsubsection{Past participation}

Past participation represents another reason why communities continue to participate in the CRS. Specifically, four respondents expressed they continue to participate in the program because they have always done so and because they did not have any reason to stop.

\subsubsection{Already doing the activities}

Three respondents mentioned they continue to participate in the CRS because they are already doing the activities. That is, they would engage in some of the activities associated with the CRS regardless of whether or not they received credit points.

\subsubsection{Flood management program maintenance, evaluation, and improvement}

Seven respondents reported they continue to participate in the CRS for flood management program maintenance, evaluation, or improvement purposes. Specifically, three respondents reported they continue to participate in the CRS to help maintain their flood management program. Another respondent reported participating in the CRS forces their community to be consistent, and another stated it gives them a reason to do better. One respondent noted that continuous participation in the CRS helps them make sure everything is in check. Finally, one respondent mentioned they continue to participate to identify best practices.

\subsubsection{Improve rating}

Improving CRS ratings represents another reason why communities continue to participate in the program. All three respondents reported they continue to participate in the program because they are interested in improving their CRS rating. One of the respondents noted that the primary motivation for improving their CRS rating is that a better rating leads to greater reductions in flood insurance premiums.

\subsubsection{Other}

Twenty responses were included under the open code, 'other.' Two of the twenty respondents stated their community's composition influences their decision to continue to participate in the program. For example, one respondent mentioned the community is a college town, and the other stated there is a large percentage of low-income residents. An additional two respondents reported copycat behavior, meaning they continue to participate in the CRS to gain knowledge on what other communities are doing and to compare success. Two additional respondents noted they continue participating due to prior success with the program. Another respondent mentioned it would look bad if their community stopped participating, and another stated participation is a status symbol. Furthermore, two respondents noted the reason for continuous participation is because they are mandated to do so. Two other respondents suggested their community had a responsibility to provide services to the public. In addition, one respondent mentioned there were networking opportunities, and another stated they were able to afford to participate in program activities. Finally, other reasons mentioned once include, but are not limited to, compliance, better coordination, management of future issues, and the minimal effort involved.

\subsection{Reasons for not participating in the CRS}

We identified six open codes for why communities do not participate in the CRS. These include lack of resources $(N=36)$, lack of benefits $(N$ $=4)$, Costs $(N=12)$, administrative burden $(N=7)$, political reasons $(N$ $=3)$, and other $(N=13)$. We were able to identify sub-codes for two of these open codes, namely lack of resources and costs. The sub-codes (in italics) we identified for lack of resources are general lack of resources $(N$ $=7)$, staff $(N=17)$, funding $(N=4)$, and time $(N=8)$. The sub-codes (in italics) for costs are general costs $(N=3)$ and costs outweigh benefits $(N=$ 9).

\subsubsection{Lack of resources}

Lack of resources represents the primary reason for not participating in the CRS. This open code contains a total of 36 responses and generated three sub-codes (in italics). Seven respondents mentioned a lack of resources in general. In addition, 17 and four respondents reported they lacked the staff or funding to participate in the program, respectively. In terms of staffing, respondents generally mentioned maintaining compliance with the CRS is a full-time job and that they are neither able to hire a new staff member or allocate a current staff member to fulfill CRS duties. Lack of time represents another resource deficiency. Eight respondents specifically reported their community simply does not have the time that is required to participate in the program and maintain compliance.

\subsubsection{Lack of benefits}

Four respondents reported they do not participate in the CRS because they experience $a$ lack of benefits. Three of these respondents specifically noted they do not have a large portion of flood insurance policyholders in their community. Hence, the incentive of reduced flood insurance premiums is not appealing. The final respondent stated the CRS offers no benefits for their community.

\subsubsection{Costs}

This open code contains a total of 12 responses that we have broken up into two sub-codes (in italics). Three respondents reported costs in general have caused their community to not participate in the CRS. The remaining nine respondents reported the costs outweigh the benefits. One respondent specifically noted they only have a couple buildings within their community that would benefit from the program.

\subsubsection{Administrative burden}

Administrative burden represents another reason why communities decide not to participate in the CRS, with seven respondents citing this reason. Administrative burden refers to the amount of paperwork that is required for participating in the program. Respondents specifically noted there is too much complexity to ensure they are maintaining compliance.

\subsubsection{Political reasons}

Three respondents mentioned they do not participate in the CRS for political reasons. One respondent stated it is up to the county board to make the decision. The other two respondents stated their local government officials were not interested in participating. One of these respondents further mentioned that local officials do not want to participate because they do not want the rights of property owners to be taken away.

\subsubsection{Other}

Thirteen responses were included under the open code, 'other.' Although a handful of these responses were irrelevant to this study's purposes, two respondents mentioned not being able to go beyond the minimum requirements set forth by the CRS. Furthermore, one respondent mentioned they have received inconsistent messaging from FEMA in terms of flood maps and floodplains. Another suggested the community's percentage of floodplains is low and that contributes to their lack of participation. Finally, one respondent mentioned there was not a large enough interest to participate, and another stated they thought it was difficult to join and that there are insufficient community regulations to warrant joining.

\section{Discussion}

This study aims to identify the unobservable factors motivating communities to initially participate in the CRS, continue to participate in the CRS, and not participate in the CRS. In terms of initial participation, most of the respondents reported they began participating in the 
CRS for the benefits, namely the reduction in flood insurance premiums. This suggests the incentive of lower flood insurance premiums is effective at motivating communities to join the program. Benefits for the community and/or homeowner was the second most common benefit identified by CRS coordinators. Responses for community and/or homeowner benefits were broad in nature but generally reflected the need to help residents and better the community. These two findings imply communities place a great deal of emphasis on the benefits community members will incur when deciding whether to participate in the CRS. This result is in line with previous research findings (e.g., Ref. [59] and FEMA's emphasis on the importance of flood insurance rate reduction as a key reward for participating in the CRS [14]. These results also align with the literature on participation in voluntary environmental programs that has shown the importance of offering benefits to increase participation [33].

Education, awareness, and/or outreach opportunities represented the second most common reason for joining the CRS. One respondent specifically mentioned the outreach efforts by personnel from FEMA and the NFIP motivated their community to join. Prior flood experience and copycatting represented two of the lesser reasons for why communities decide to join the CRS. The low number of responses for these two reasons is somewhat surprising since existing research has shown having a high flood risk, and therefore higher likelihood of experiencing flood disasters, is a significant predictor of CRS participation [9,16-20,46,59]. Similarly, scholars have found CRS participating communities tend to cluster together (e.g., Ref. [17,46,60] and engage in copycatting [61].

The reasons for continued CRS participation are very similar to those of initial participation. Again, the benefits and more specifically, the reductions in flood insurance premiums remain the primary reasons why communities continue to participate in the CRS. This provides further evidence to suggest the reduced flood insurance premiums is an enticing strategy for getting communities to join the CRS and for maintaining participation. Improving land use, strengthening local ordinances, and preserving natural areas represented the second most mentioned benefit for continued participation. Two other common benefits for continued participation include the benefits that community and/or homeowner continue to receive as well as improvement in flood mitigation, protection, and response. It is interesting to note the number of responses for the latter benefit doubled from initial participation to continued participation. This might suggest communities continue to participate in the program as they reap the benefits of some of the more long-term flood mitigation and protection projects associated with CRS participation. That is, such benefits might not be fully apparent to communities when deciding whether to join the CRS, perhaps because they are not emphasized as the benefits of participation in the CRS by FEMA in publication materials used to promote the CRS (e.g., CRS Fact Sheet).

Similar to initial participation, education, awareness, and/or outreach opportunities represented the second most common reason for continued CRS participation. This was followed by flood management program maintenance, evaluation, and improvement. This reason indicates communities continuing CRS participation might view the CRS as a mechanism for maintaining or a catalyst for improving their floodplain management activities. Political reasons, past participation, already doing the activities, and improving CRS ratings represented important but lesser reasons for why communities decide to continue to participate in the CRS. Whereas past participation and already doing the activities appear to underscore how, in some communities, participation in the CRS can become a habit or routine, political reasons emphasize the benefits of having support from local elected officials. Finally, the desire to improve CRS ratings suggests participating communities are invested in the CRS, and they continue to participate in the program because they may be interested in receiving the benefits associated with a better rating like further reductions in flood insurance premiums.

In terms of non-CRS participation, most of the respondents reported they do not participate in the CRS due to a lack of resources, specifically due to a lack of staff. Time and funding issues represented additional resource constraints. A lack of organizational capacity is also a common factor impacting participation in voluntary environmental programs [35]. Relatedly, a handful of respondents reported they do not participate due to the administrative burden, referring to the significant amount of paperwork that is required for participation. These findings are not surprising as maintaining compliance with the CRS can be tedious and time-consuming. For example, to join the CRS, communities must show they have been in full compliance with the rules and regulations of the NFIP for the past year, and if a community is interested in continuing their participation, they must recertify each year [14].

The costs associated with participation represented an additional reason why communities choose not to participate in the CRS. The majority of these respondents mentioned the costs outweighed the benefits of participation. A possible explanation for this is that these communities might have limited flood exposure and, subsequently, fewer flood insurance policyholders. As a result, these communities might then also lack the initial impetus needed to begin and continue to participate in the CRS. Other respondents reported they do not participate in the CRS because of the lack of benefits, namely the reduction in flood insurance premiums. Again, this could be because of the low percentage of flood insurance policyholders in their community. These findings align with the broader literature on participation in voluntary environmental programs, showing that participation is higher when the benefits are greater than the costs [33]. Finally, a few respondents mentioned they do not participate in the CRS for political reasons, with the majority stating local elected officials are not interested in the program.

In addition to discussing respondents' reasons for initial, continued, or non-participation in the CRS, it is important to discuss some reasons respondents did not bring up during the interviews. Surprisingly, only one community cited the networking opportunities as a reason for continued participation. This is unexpected since FEMA identifies being granted access to the CRS User Groups as a major benefit of participation [14]. The purpose of the CRS Users Groups is to provide a place of support for communities as they implement their floodplain management activities. It is also surprising that although non-CRS communities largely indicated they do not have the resources to participate in the program, they did not mention they perceive the process of participation to be difficult. While this could be because they are not fully aware of the process, it might mean they are used to dealing with such administrative challenges and that the process is not too taxing.

\section{Conclusion}

The goal of this study was to better understand the unobservable predictors of communities' initial participation, continuous participation, and non-participation in FEMA's CRS program. To achieve this goal, this study used PSM to match 100 randomly selected CRS participating communities with 100 non-CRS participating communities and collected data from 100 CRS coordinators in the CRS participating communities and 100 floodplain managers from the non-CRS participating communities via phone interviews.

The results indicate several unobservable factors are responsible for why communities initially participate, continue to participate, or do not participate in the CRS. The reasons for initially participating in the CRS include: the benefits of participation (e.g., to reduce flood insurance premiums; to address flood risks and reduce flood losses; to provide flood mitigation, protection, and response; to improve land use, strengthen local ordinances, and preserve natural areas; to provide benefits to the community and/or homeowners; and to save costs); education, awareness, and/or outreach; copycatting; and prior flood experience. The following were given as the reasons for continuing to participate in the CRS: benefits (e.g., to reduced flood insurance premiums; to provide flood mitigation, protection, and response; to address flood risks and reduce future flood losses; to improve land use, strengthen local ordinances, and preserve natural areas; to provide 
benefits to the community and/or homeowners; and to save costs); education, outreach, and/or awareness; political reasons; past participation; already doing the activities; flood management program maintenance, evaluation, and improvement; and improve rating. Finally, the reasons for non-participation in the CRS include: lack of resources (staff, funding, and time); lack of benefits; costs (costs outweigh benefits); administrative burden; and political reasons.

The results of this study lend themselves to a handful of policy implications. First, to increase CRS participation, focus should be placed on advertising and promoting the reductions in flood insurance premiums for policyholders in their community. The results also indicate that possibly the best time to advertise the benefits of CRS participation is in the aftermath of a flood disaster. Second, given that the primary reason for not participating in the CRS is a lack of resources, namely a lack of staff, funding, and time, CRS program managers should aim to identify mechanisms that improve processes and reduce administrative burden while simultaneously maintaining the integrity of the program. Third, there are opportunities to tie the CRS to other mitigation programs like FEMA's Pre-Disaster Mitigation (PDM) and Building Resilient Infrastructure for Communities (BRIC) grant programs. FEMA could, for example, share the costs for communities to participate in the CRS by setting cost-matching rates similar to those under the PDM grant program (i.e., FEMA covers $75 \%$ of costs and communities provide a $25 \%$ match). Finally, FEMA can consider partnering with states to develop revolving loan funds [62]. Revolving loan funds represent a lending arrangement whereby the federal government partners with states to offer low-interest loans to local communities. As communities repay their loans, they replenish the revolving fund so that loans can be provided to new communities to fund new projects. Instituting a revolving loan fund could help communities interested but lacking the funding to participate in the CRS with the initial funds needed to participate.

Although using PSM to match communities and develop nearly identical treatment/CRS groups and untreated/non-CRS groups relaxes most threats to validity, there are a few limitations worth mentioning. A major limitation of this study is the inability to audio-record the interviews and produce interview transcripts. Having interview transcripts would have allowed the researchers to do a more thorough and richer text analysis. An additional limitation of the study is that the interviews were relatively short. It would be wise for researchers to conduct more in-depth interviews with a set of CRS coordinators and floodplain managers to further understand the unobservable factors motivating them to participate or not participate in the CRS. Finally, we cannot generalize the findings to the broader population. The PSM matching approach was specifically used so that we could compare communities on the margin of joining or not joining the CRS. Researchers should employ techniques that would enable the findings of future studies to be generalizable to the broader population.

Despite these limitations, this paper is an important contribution to the community flood risk management literature in general and the CRS literature in particular. Indeed, this study sheds light on the unobservable factors on why communities choose to participate or not to participate in federal voluntary programs in domains other than flood risk management such as environmental protection (e.g., United States Environmental Protection Agency's voluntary air pollution programs). The information presented here can help the flood risk management community develop better policies and practices aimed at increasing participation, improving flood risk management, and enhancing community resilience to future disasters.

\section{Declaration of competing interest}

The authors declare that they have no known competing financial interests or personal relationships that could have appeared to influence the work reported in this paper.

\section{Acknowledgment}

This article is based on research funded by the US National Science Foundation (NSF) Grant No. 1838421. The findings and opinions are those of the authors and do not necessarily represent the NSF.

\section{Appendix A. Supplementary data}

Supplementary data to this article can be found online at https://doi. org/10.1016/j.ijdrr.2020.101574.

\section{References}

[1] B.A. Cigler, US floods: the necessity of mitigation, State Local Govern. Rev. 49 (2) (2017) 127-139.

[2] National Weather Service, Flood Damage/costs/fatalities, 2018. Retrieved from, https://www.ncdc.noaa.gov/stormevents/.

[3] United States Geological Services, 2016 Flood Events August Louisiana Floods, 2017. Retrieved from, https://water.usgs.gov/floods/events/2016/aug_la/.

[4] United States Geological Services, Post Harvey Report Provides Inundation Maps and Flood Details, 2018. Retrieved from, https://www.usgs.gov/news/post-harve y-report-provides-inundation-maps-and-flood-details-largest-rainfall-event-recorde d.

[5] E.O. Michel-Kerjan, A. Atreya, J. Czajkowski, Learning over Time from FEMA's Community Rating System (CRS) and its Link to Flood Resilience Measurement, 2016. Retrieved from, http://opim. wharton.upenn.edu/risk/library/WP2016 11-Learning-Over-Time-CRS.pdf.

[6] J. Tyler, A.A. Sadiq, D.S. Noonan, A review of the community flood risk management literature in the USA: lessons for improving community resilience to floods, Nat. Hazards 96 (3) (2019) 1223-1248.

[7] S.D. Brody, S. Zahran, P. Maghelal, H. Grover, W.E. Highfield, The rising costs of floods: examining the impact of planning and development decisions on property damage in Florida, J. Am. Plann. Assoc. 73 (3) (2007) 330-345.

[8] S.D. Brody, S. Zahran, W.E. Highfield, H. Grover, A. Vedlitz, Identifying the impact of the built environment on flood damage in Texas, Disasters 32 (1) (2008) 1-18.

[9] Q. Fan, M. Davlasheridze, Evaluating the effectiveness of flood mitigation policies in the US. Conference paper. Agricultural and Applied Economics Association Annual Conference, 2014.

[10] W.E. Highfield, S.D. Brody, R. Blessing, Measuring the impact of mitigation activities on flood loss reduction at the parcel level: the case of the clear creek watershed on the upper Texas coast, Nat. Hazards 74 (2) (2014) 687-704.

[11] H. Kim, Exploring the Role of Community Capacity and Planning Effort in Disaster Risk Reduction and Environmental Sustainability: Spatio-Temporal Vulnerability and Resiliency Perspectives, Doctoral Dissertation, The University of WisconsinMadison, 2015.

[12] J. Li, Community Flood Hazard Mitigation and the Community Rating System of National Flood Insurance Program, Dissertation, East Carolina State University, 2012.

[13] S. Zahran, S.D. Brody, W.G. Peacock, A. Vedlitz, H. Grover, Social vulnerability and the natural and built environment: a model of flood casualties in Texas, Disasters 32 (4) (2008) 537-560.

[14] Federal Emergency Management Agency, Community Rating System Coordinator Manual, 2017. Retrieved from, https://www.fema.gov/media-library-data/1493 905477815-d794671adeed5beab6a6304d8ba0b207/633300_2017_CRS_Coordina tors_Manual_508.pdf. (Accessed 4 July 2018).

[15] B.A. Lundgren, F.Y. Wallentin, Measuring unobservable factors in residential developments: a structural equation approach, J. Eur. Real Estate Res. 9 (3) (2016) 250-272.

[16] E.A. Asche, The Effect of Flood Risk on Housing Choices and Community Hazard Mitigation, Dissertation, University of California, Santa Barbara, 2013.

[17] C.E. Landry, J. Li, Participation in the community rating system of NFIP: empirical analysis of North Carolina counties, Nat. Hazards Rev. 13 (3) (2011) 205-220.

[18] J. Posey, Coping with Climate Change: toward a Theory of Adaptive Capacity, Doctoral Dissertation, Rutgers The State University of New Jersey-New Brunswick, 2008.

[19] J. Posey, The determinants of vulnerability and adaptive capacity at the municipal level: evidence from floodplain management programs in the United States, Global Environ. Change 19 (4) (2009) 482-493.

[20] A.A. Sadiq, D.S. Noonan, Flood disaster management policy: an analysis of the United States Community Ratings System, J. Nat. Resour. Pol. Res. 7 (1) (2015) $5-22$.

[21] A.A. Sadiq, J. Tyler, D.S. Noonan, R.K. Norton, S.E. Cunniff, J. Czajkowski, Review of the Federal Emergency Management Agency's Community Rating System Program, Nat. Hazard. Rev. 21 (1) (2020) 03119001.

[22] S.E. Cunniff, Improving FEMA's Community Rating System to encourage investment in coastal natural infrastructure to reduce storm damages, Shore Beach 86 (2) (2018) 27-32.

[23] CRS Resources, The Community CRS Coordinator, 2012. Retrieved from, https ://crsresources.org/files/200/crs_coordinator.pdf.

[24] V. Haufler, A Public Role for the Private Sector: Industry Self-Regulation in a Global Economy, Carnegie Endowment for International Peace, Washington, DC, 2013. 
[25] T.H. Arimura, A. Hibiki, H. Katayama, Is a voluntary approach an effective environmental policy instrument? A case for environmental management systems, J. Environ. Econ. Manag. 55 (3) (2008) 281-295.

[26] T.P. Lyon, J.W. Maxwell, Voluntary approaches to environmental regulation: a survey, in: M. Franzini, A. Nicita (Eds.), Environmental Economics: Past, Present and Future, Ashgate Publishing, Hampshire, 1999.

[27] M. Potoski, A. Prakash, Green clubs and voluntary governance: ISO 14001 and firms' regulatory compliance, Am. J. Polit. Sci. 49 (2) (2005) 235-248.

[28] P.R. Berke, Reducing natural hazard risks through state growth management, J. Am. Plann. Assoc. 64 (1) (1998) 76-87.

[29] S. Arora, T.N. Cason, An experiment in voluntary environmental regulation: participation in EPA's 33/50 program, J. Environ. Econ. Manag. 28 (3) (1995) 271-286.

[30] N. Darnall, Motivations for participating in a voluntary environmental initiative: the multi-state working group and EPA's EMS pilot program, in: S. Sharma, M. Starik (Eds.), Research in Corporate Sustainability: the Evolving Theory and Practice of Organization in the Natural Environment, Edward Elgar Publishing, Boston, 2002, pp. 123-154.

[31] N. Darnall, S. Sides, Assessing the performance of voluntary environmental programs: does certification matter? Pol. Stud. J. 36 (1) (2008) 95-117.

[32] M. Delmas, A. Keller, Free riding in voluntary environmental programs: the case of the US EPA WasteWise program, Pol. Sci. 38 (2) (2005) 91-106.

[33] M. Khanna, Non-mandatory approaches to environmental protection, J. Econ. Surv. 15 (3) (2001) 291-324.

[34] A. Alberini, K. Segerson, Assessing voluntary programs to improve environmental quality, Environ. Resour. Econ. 22 (1) (2002) 157-184.

[35] J. Videras, A. Alberini, The appeal of voluntary environmental programs: which firms participate and why? Contemp. Econ. Pol. 18 (4) (2000) 449-460.

[36] Environmental Protection Agency, About WasteWise, Retrieved from, http ://www3.epa.gov/epawaste/conserve/smm/wastewise/about.htm, 2014.

[37] Sadiq, A. A., Tyler, J., Noonan, D. S., Norton, R. K., Cunniff, S. E., Czajkowski, J. (forthcoming). A review of the federal emergency management Agency's community rating system program. Nat. Hazards Rev..

[38] S.D. Brody, W.G. Peacock, J. Gunn, Ecological indicators of flood risk along the Gulf of Mexico, Ecol. Indicat. 18 (2012) 493-500.

[39] C. Kousky, E. Michel-Kerjan, Examining flood insurance claims in the United States: six key findings, J. Risk Insur. 84 (3) (2017) 819-850.

[40] E.O. Michel-Kerjan, C. Kousky, Come rain or shine: evidence on flood insurance purchases in Florida, J. Risk Insur. 77 (2) (2010) 369-397.

[41] D.R. Petrolia, C.E. Landry, K.H. Coble, Risk preferences, risk perceptions, and flood insurance, Land Econ. 89 (2) (2013) 227-245.

[42] S.D. Brody, W.E. Highfield, Open space protection and flood mitigation: a national study, Land Use Pol. 32 (2013) 89-95.

[43] S.D. Brody, S. Zahran, W.E. Highfield, S.P. Bernhardt, A. Vedlitz, Policy learning for flood mitigation: a longitudinal assessment of the community rating system in Florida, Risk Anal.: Int. J. 29 (6) (2009) 912-929.

[44] Q. Fan, M. Davlasheridze, Flood risk, flood mitigation, and location choice: evaluating the national flood insurance program's community rating system, Risk Anal. 36 (6) (2016) 1125-1147.

[45] W.E. Highfield, S.D. Brody, Evaluating the effectiveness of local mitigation activities in reducing flood losses, Nat. Hazards Rev. 14 (4) (2012) 229-236.
[46] J. Li, C.E. Landry, Flood risk, local hazard mitigation, and the community rating system of the national flood insurance program, Land Econ. 94 (2) (2018) $175-198$.

[47] R. Blessing, A. Sebastian, S.D. Brody, Flood risk delineation in the United States: how much loss are we capturing? Nat. Hazards Rev. 18 (3) (2017), 04017002.

[48] S.D. Brody, Y. Lee, W.E. Highfield, Household adjustment to flood risk: a survey of coastal residents in Texas and Florida, United States, Disasters 41 (3) (2017) $566-586$.

[49] M. Paille, M. Reams, J. Argote, N. Lam, R. Kirby, Influences on adaptive planning to reduce flood risks among parishes in South Louisiana, Water 8 (2) (2016) 57-71.

[50] A.A. Sadiq, D. Noonan, Local capacity and resilience to flooding: community responsiveness to the community ratings system program incentives, Nat. Hazards 78 (2) (2015) 1413-1428.

[51] J. Tyler, The Relationship between the Community Rating System Program and Business Disaster Recovery. Natural Hazards Center, 2018. Retrieved from, https ://hazards.colorado.edu/quick-response-report/the-relationship-between-the -community-rating-system-program-and-business-disaster-recovery.

[52] J. Tyler, A.A. Sadiq, Business continuity and disaster recovery in the aftermath of hurricane Irma: exploring whether community-level mitigation activities make a difference, Nat. Hazards Rev. 20 (1) (2018) 1-12.

[53] D.S. Noonan, A.A. Sadiq, Flood risk management: exploring the impacts of the community rating system program on poverty and income inequality, Risk Anal. 38 (3) (2018) 489-503.

[54] D.S. Noonan, A.A. Sadiq, Community-scale flood risk management: effects of a voluntary national program on migration and development, Ecol. Econ. 157 (2019) 92-99.

[55] Federal Emergency Management Agency, Floodplain Managers, 2018. https://www.fema.gov/floodplain-managers.

[56] Association of State Floodplain Managers, Model Job Description for a Community Floodplain Manager, 2010. Retrieved from, https://www.floods.org/ace-files/ documentlibrary/CFM/FPM_Model_Job_Description_2010.pdf.

[57] S. Zahran, S.D. Brody, W.E. Highfield, A. Vedlitz, Non-linear incentives, plan design, and flood mitigation: The case of the federal emergency management agency's community rating system, J. Environ. Plan. Manag. 53 (2) (2010) 219-239, https://doi.org/10.1080/09640560903529410.

[58] S.M. Ravitch, N.M. Carl, Qualitative Research: Bridging the Conceptual, Theoretical, and Methodological, Sage Publications, 2016.

[59] K. Ronneberg, The Federal Emergency Management Agency's Community Rating System; Evaluating its Functionality as a Robust Climate Change Adaptation Strategy. Master's Project, Duke University, 2014. Retrieved from, http://hdl.ha ndle.net/10161/8492.

[60] Noonan, D. S., Richardson, L. E., Sadiq, A. A., \& Tyler, J. (forthcoming). What drives community flood risk management? Policy diffusion or free-riding. Int. J. Sustain. Dev. Plann..

[61] D.S. Noonan, L.E. Richardson, A.A. Sadiq, Policy diffusion in community-scale flood risk management, WIT Trans. Eng. Sci. 121 (2018) 81-92.

[62] Pew Charitable Trusts, State Revolving Loan Fund Gains Momentum in Congress, 2018. Retrieved from, https://www.pewtrusts.org/en/research-and-analysis/arti cles/2018/12/12/state-revolving-loan-fund-gains-momentum-in-congress. 